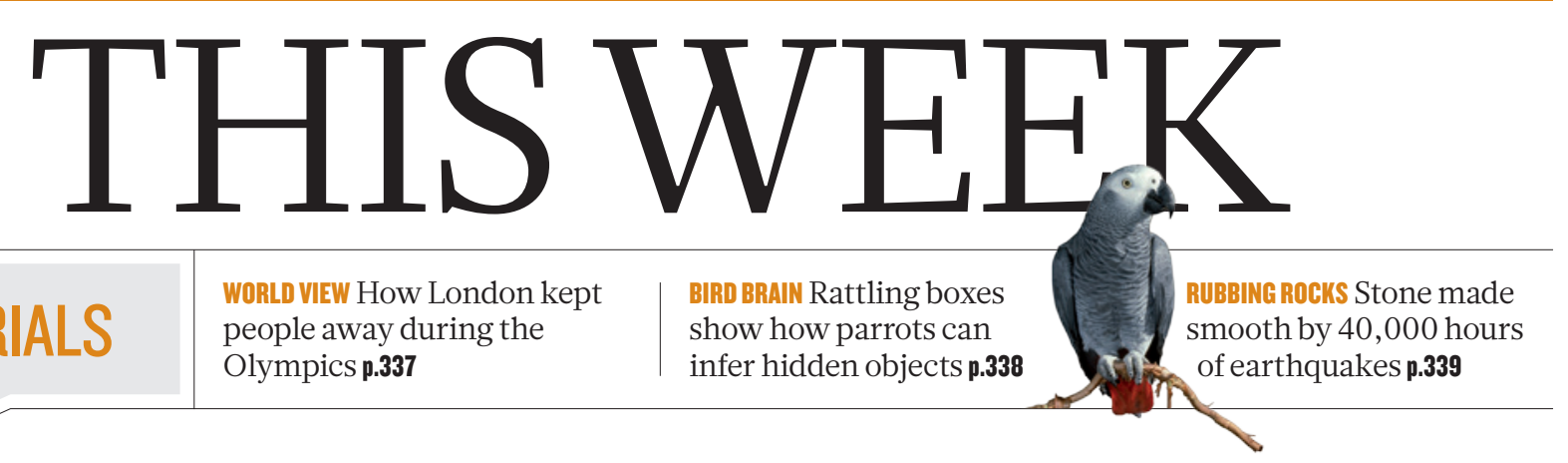

EDITORIALS people away during the show how parrots can infer hidden objects $\mathbf{p . 3 3 8}$

\title{
Through the gaps
}

\section{A 20-year campaign of scientific fraud says as much about the research community as it does about the perpetrator. The system that allowed such deception to continue must be reformed.}

$\mathrm{M}$ any questions are provoked by the shocking case of Yoshitaka Fujii, the Japanese anaesthesiologist who seems likely to set a record for the highest number of retracted papers by a single scientist. His entire list of publications has come under scrutiny: his trail of deception seems to have wound through almost 200 scientific articles over 20 years. Twenty years! How could it go on for so long?

As the News story on page 346 details, Fujii seems to have fabricated multiple studies wholesale, in some cases inventing participants. Nobody noticed - not his collaborators, funders, home institutions or journal editors. Or at least, nobody took action.

In retrospect, as in all cases of scientific fraud, the bulk of the questions will, rightly, focus on how to make sure that it cannot happen again. That, and why so much time passed before anyone investigated how Fujii was publishing clinical studies at impossible speed.

Fujii pulled the wool over the eyes of many different people - chief among them, various employers, whom he also falsely claimed had approved his studies, and journal editors. (One editor has publicly issued a mea culpa.) Perhaps most puzzling is that Fujii fooled his co-authors, one of whom published dozens of papers with him. The co-authors say that they had no suspicions; the Japanese Society of Anesthesiologists, which had a key role in exposing Fujii's fraud, is investigating.

But let's be honest. Even assuming that any co-author had suspicions, the current system means that it would not have been easy to raise the alert. It can be difficult to document a colleague's errant ways, and whistle-blowers might put their own careers at risk by angering a senior member of the field.

Those who inform authorities about other types of fraud sometimes get rewards. For example, the US government last week paid out its and probably the world's - biggest ever payment to a whistle-blower. The former banker, who was jailed for his own role in a tax-evasion scandal, received US\$104 million. Observers - especially lawyers are pointing out that such windfalls might be the only way to encourage more insiders to put their necks on the line, which remains the most effective way to protect against such crimes.

That method is probably unworkable in science. Funders won't have that kind of cash to throw at scientific whistle-blowers. And imagine the uproar, not least in these pages, if whistle-blowers routinely got payouts bigger than the grants available for science projects through competitive peer review.

In the tax-evasion case, the figure was justified because it was only a small fraction of what the US government was able to recoup. But governments should also consider the amount of waste incurred by research fraud, especially when that fraud is carried out over decades and enshrouded in the scientific literature. On financial grounds alone, there are sound reasons for the authorities to increase the resources

invested in efforts to limit academic misconduct, without the need to provide monetary rewards.

Japan, for example, could make it easier for whistle-blowers to take their claims to an external body, rather than to their employers. In theory, the country already has such a system. But in practice, agencies at the relevant ministries merely forward claims to the institu-

"On financial grounds alone, there are sound reasons for the authorities to increase the resources invested in efforts to limit academic misconduct."

misconduct."
tions involved, leaving whistle-blowers vulnerable.

In the wake of the latest scandal, there are signs of positive change. The Japanese Society of Anesthesiologists was so frustrated at the lack of an effective whistle-blowing mechanism that it plans to establish one. A group of 23 journal editors deserves credit for effectively, if belatedly, rooting out Fujii's problematic publications. And statistical approaches to evaluating results - such as those used to show that Fujii's data were far too perfect - are becoming more familiar, more readily available and, hopefully, more accepted as a legitimate way to audit published findings and raise red flags where necessary.

It is important to note that although this latest case of fraud seems (again) to be an anomalous, extreme example involving one individual, the problems that allowed it to persist are endemic in scientific communities around the world. It is equally important to say (again) that they must be addressed in comprehensive fashion.

\section{Extreme weather}

\section{Better models are needed before exceptional events can be reliably linked to global warming.}

A s climate change proceeds - which the record summer melt of Arctic sea-ice suggests it is doing at a worrying pace nations, communities and individual citizens may begin to seek compensation for losses and damage arising from global warming. Climate scientists should be prepared for their skills one day to be probed in court. Whether there is a legal basis for such claims, such as that brought against the energy company ExxonMobil by the remote Alaskan community of Kivalina, which is facing coastal erosion and flooding as the sea ice retreats, is far from certain, however. So lawyers, insurers and climate negotiators are watching with interest the emerging ability, arising from improvements in climate models, 